\title{
Postgraduate Research Supervision: An 'Agreed' Conceptual View of Good Practice through Derived Metaphors
}

\author{
Kevin Grant \\ London South Bank University, \\ London, UK \\ kevin.grant@Isbu.ac.uk
}

\author{
Ray Hackney \\ Brunel University, \\ Middlesex, UK
}

ray.hackney@brunel.ac.uk

\section{David Edgar \\ Glasgow Caledonian University, Glasgow, UK \\ d.a.edgar@gcu.ac.uk}

\begin{abstract}
The paper explores the role of the postgraduate supervisor through advising, mentoring, and monitoring for the varied and complex process towards successful doctoral thesis completion. There is a scarcity of research into this important area, and we therefore undertake a comprehensive literature review to determine the current state of knowledge and international approaches. This involved an initial analysis of policy documents from European and Australian universities to provide insights into institutional norms. Primary data collection was then collected through surveys and personal interviews with a range of experienced academics involved in postgraduate supervision. We identify three metaphors related to a 'machine', 'coach' and 'journey' as critical perspectives towards professional student engagement. Our findings are believed to be of benefit to academics and doctoral candidates involved in challenging and original research.
\end{abstract}

Key Words: Research supervision, Postgraduate research, Metaphor, Conceptual model, Academic practice.

\section{Introduction}

Postgraduate research is an ever changing and complex area of activity. For a number of years, researchers, practitioners, and professionals have attempted to understand and make sense of the world from varying perspectives with research supervision noted as a particularly challenging

Material published as part of this publication, either on-line or in print, is copyrighted by the Informing Science Institute. Permission to make digital or paper copy of part or all of these works for personal or classroom use is granted without fee provided that the copies are not made or distributed for profit or commercial advantage AND that copies 1) bear this notice in full and 2) give the full citation on the first page. It is permissible to abstract these works so long as credit is given. To copy in all other cases or to republish or to post on a server or to redistribute to lists requires specific permission and payment of a fee. Contact Publisher@InformingScience.org to request redistribution permission. engagement. This paper seeks to unpack the issues of what enables effective postgraduate level research supervision.

Post Graduate degrees in the UK are awarded to students who have demonstrated the following: a systematic understanding of knowledge, and a critical awareness of current problems and/or new insights, much of which is at, or informed by, the forefront of their aca- 
demic discipline, field of study or area of professional practice; a comprehensive understanding of techniques applicable to their own research or advanced scholarship; originality in the application of knowledge, together with a practical understanding of how established techniques of research and enquiry are used to create and interpret knowledge in the discipline; conceptual understanding that enables the student to evaluate critically current research and advanced scholarship in the discipline and to evaluate methodologies and develop (Quality Assurance Agency for Higher Education, 2008).

The substantive investigation was undertaken to address the perceived gap in the knowledge base relating to the supervision of research students by examining academic experiences and determining what constitutes 'good research supervision'. We attempted to clarify normally unarticulated assumptions within natural conditions and settings to yield insights into the area, from the specific viewpoint of the supervisor.

Consequently, an agreed view is presented of what potentially makes a good research supervisor. The paper does not offer a complete solution, but more a deconstruction of practice, which does not provide final outcomes (Stronach \& MacLure, 1997). It is anticipated that these insights will help faculty to reflect upon their own professional practice and move some way towards ensuring that students receive a consistent, focused and effective research learning experience.

\section{Literature Review \& Policy Document Analysis}

Siddle (2001) posits that the education and training of postgraduate students is one of the most important functions of any university. He states that this task is deceptively simple; to train successive generations of students and researchers who are capable of innovative and pragmatic research across the spectrum from fundamental, to user inspired, to applied research in a variety of educational, research and development, commercial and industry contexts (Siddle, 2001). The actual process and mechanics of doing research, especially the supervision is not unequivocal and is known to be extremely challenging (Anderson, Day, \& McLaughlin, 2006).

Supervision practices are not simply prescribed by institutional policies. Research supervision is fluid and is determined by continuity and change. How the individual supervisor inherits and reproduces what is considered good research within a discipline is dependent on traditions, customs, and beliefs. Todd, Smith, and Bannister (2006) when exploring the task of being a research supervisor suggest that it is very much a contested terrain in terms of academic professional practice and that it also helps to shape an academic's identity. How supervisors will interpret the traditions of the academy and the notions of how to do 'good' disciplinary based research is based on academic disciplinary traditions, customs, and practices based on their own ontological, political, epistemological, and ideological background.

More often than not, supervisors tend to bring their own particular slant on how they interpret both the institutional rhetoric and the hidden assumptions contained within their own cognate area. Lave and Wagner (1991) suggest supervisors learn and interpret the knowledge base for that community of practice if they are to be accepted as a member of that community.

The topic of postgraduate dissertation supervision has not, as noted, been investigated in any significant depth to consider the research supervision process and to help reveal any 'secret formulas or holy grails' that may exist to inform professional practice. The most notable exception here is the work of Anderson et al (2006). They explored the area of dissertation research drawing on a number of sources from practices and literature. Their article suggests that a major issue rests with the student requiring a strong directive approach. Here, the supervisor is required to follow guidance and control policy with the wish to encourage an enquiring and creative approach (shaping versus supporting) by the student whilst achieving academic standards set by the university. 
Moses $(1985,1992)$ states that most supervisory problems can be overcome if there is clear and open dialogue on all aspects of the project. As such, there should be a structure in place as to what is expected of the student and a framework for supervision which facilitates rather than hinders development and creativity. Moses (1992) traditionally advocates three distinct stages of supervisor involvement: helping the student to choose a viable topic and initiate data collection (intensive), monitoring student progress (less intensive), and writing up (intensive). It would appear that supervisors can interpret how to supervise as ever they wish, regardless of their level of expertise, their awareness of the subject matter, or their own experience of supervising different types of students with different learning needs and aspirations. It is evident that they control and command the scholarship for research supervision, which may be counter to sector wide, university or even disciplinary good practice.

\section{Theoretical Lens}

Cullen, Pearson, and Saha (1994) report that there are certain key generic processes in supervising $[\mathrm{PhD}]$ students effectively. They also indicate that due to disciplinary boundaries, the actual process and therefore the 'best practices' exhibited differ across related areas of study and, taking this point further, between Universities with different mission statements and value propositions. Cullen et al.'s work is supported by Black (1994), who stated that the actual relationship between the student and the supervisor is the key that enables effective supervision to occur. In addition, having good dialogue between the supervisor and the student obviously helps to enable a positive learning experience for the research student (Todd et al, 2006). The concept of good here is taken to be Platonic in the sense that it is something we strive for, but given the imperfections of language and in our ability to understand our student's needs, we rarely achieve and to be surpassing in the sense of better than all the rest do it, and this is recognised by common consent and by an external referent.

Many of the discussions in the literature contend that the minimum requirements for research supervision are based on the work of Vitae (www.vitae.ac.uk).

1. Supervisory style (correct level of direction, regular meetings, making time for students, interest in project, encourage ideas/individuality);

2. Supervisor competence with respect to the student project; personal characteristics and attitude of the supervisor (approachable, supportive, positive, open-minded, prepared to acknowledge error, organised, enthusiastic);

3. Academic and intellectual standing of the supervisor; that students view their supervisors as mixtures of strengths and weaknesses; in addition, those student-supervisor relationships are highly complex, dynamic and relational.

\section{New Managerialism}

During the 1990s, as the higher education sector in the UK continued to expand, institutions came under increasingly competitive pressures. New universities were created, new programmes of study were developed and access widened to include previously disadvantaged sections of the population. These changes were accompanied by explicit demands from the government for clear mechanisms of quality assessment and enhancement with robust quality control procedures from which some authors have coined the phrase 'New Managerialism' (Clarke \& Newman (1997). Within this backdrop of activities, universities attempted to develop new programmes of study to satisfy the diverse and growing demands of students and to support the government's expansion policy. It must also be stressed that this New Managerialism in the UK has now spread to other countries such as Canada, Australia, and Ireland (Lynch, Grummell, \& Devine, 2012). 
The need for accountability and compliance, or to follow a tick box mentality (Corbyn, 2009), is prevalent in the ideology of New Managerialism (Kolsaker, 2008; Pollitt, 1990). Researchers have suggested that this has rooted itself into the higher education academy in a pedestrian banal way. New Managerialism seeks to maintain and enhance the three 'Es' of efficiency, effectiveness, and efficacy by adopting private sector managerial techniques to 'manage' public sector work and actions, and seeks to ensure quality and to make professionals accountable and responsible for their actions (Grant, Hackney, \& Edgar, 2003).

Nevertheless, elements of New Managerialism may have helped to reduce wastage in the academy. It may also have helped many students to receive a basic level of supervision, by right and entitlement, rather than some students receiving little or inappropriate research supervision. Therefore, the use of policy documents does have both a positive and negative slant on research supervision. This 'institutional requirement' is further compounded by the supervisors' view of themselves in terms of their ideological and intellectual belief system and of course their own experience of being 'supervised'. Having outlined the idea of increased accountability as expressed by New Managerialism, it is important to establish if this mentality exists today.

\section{Policy Document Analysis}

The following is a synthesis (using the Policy Circle Ps) of the 'official' duties and responsibilities as prescribed by internal university policy makers. These policy documents were sourced from Monash University, University of Sydney, Glasgow Caledonian University, Robert Gordon University, and the University of Groningen (see the Appendix). These were selected as they were freely available online and represent a convenience based sample.

Each University's policy document was analysed using a simplified version of what Silverman (2000) describes as the constant comparative method whereby:

- a sample of responses was read;

- points of similarity and difference were noted;

- categories were generated: these categories were then tested against a new set of responses;

- new categories were then generated and tested against responses already analysed;

- all existing categories were carried forward to new responses; and

- the process was repeated until all responses had been examined and all categories tested against all responses.

This method has been used previously in educational research by Brown and McIntyre (1993) and also by Cooper and McIntyre (1996), although they termed it "recursive comparative analysis".

Policy document analysis, using the Policy Circle Ps, is the evaluation of either an internal or an external policy statement using a set of criteria that reflects different social, political, and economic dimensions in order to determine the policy's value and how this may impact on practice. The approach used in this research was the Policy Circle 'Ps' (Hardee, Feranil, Boezwinkle, \& Clark, 2004).

This approach can be described as focusing on the problem the policy document is seeking to address and what aim of the policy is it trying to satisfy/address within the landscape it was developed in and for. The second $\mathrm{P}$ is the people who are the stakeholders, actors, agents, and shareholders in the policy network and whose agenda is being satisfied (both overtly and covertly) by the policy. This is followed by the next $\mathrm{P}$ of Place. Place is to review a policy document to ascertain how much foreground and background is given to each player/agent/agency contained within the policy, to see who has pride of place and why. This is followed by an explo- 
ration of the actual Policy making, i.e., how was the policy developed and implemented; this P was not adopted for this study along with the Price Tag P, i.e., what is the cost of the policy options and how resources are allocated. This was due not having sufficient access to the policy makers and how they implemented the policy within their respective Universities. The next P of the Policy Circle is that of Paper, what is actually stated in the policy as the outcome or impact or value adding, or benefits to both stake and shareholders. The final two Ps are that of Programs and Performance; the programs are what has resulted from implementing policies, and performance is concerned with asking what is being explicitly covered in and by the policy. These last two Ps were not covered in this study. This was due to not being able to access the 'behind the scenes' activities in the host organisations where the research supervisor policy documents originated from. Table 1 outlines a proposed approach which should be adopted during research student supervision.

\section{Table 1: Outcome of Policy Circle Approach}

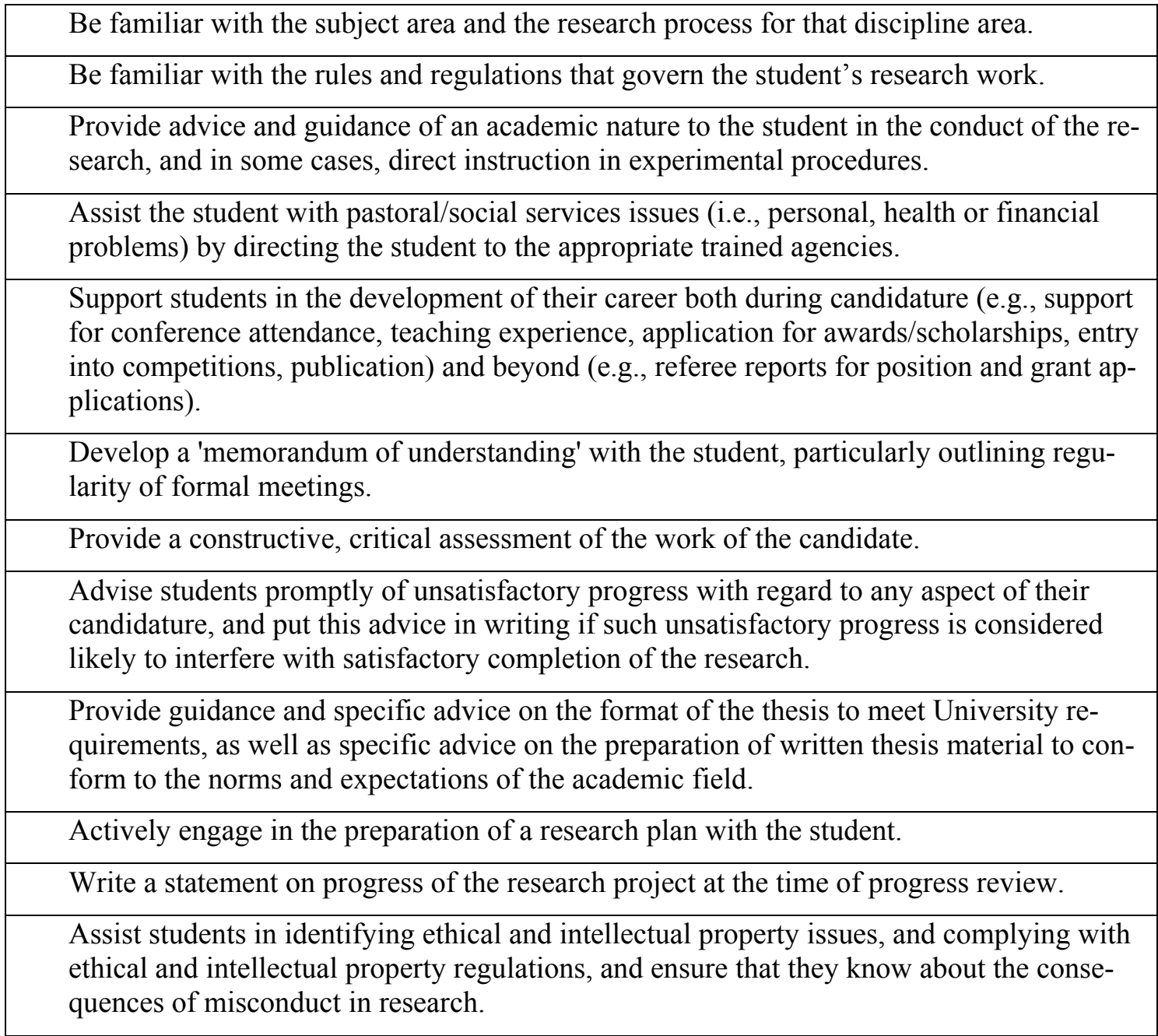

The managerialist language of "supervisors must do" and "supervisors should ensure" in the policy documents gives the idea or metaphor of research supervision being an institutional act. Common statements contained in the documents like "all supervisors are aware of the necessity to implement the university's code of practice for the conduct of research and are aware of the working procedures of the ethics committees" are frequently included in policy documents. 
Supervisors may feel the need to battle with the rules and regulations for not being able to accommodate the unusual or the unique, as policy documents tend to cater for the 'average student' or 'the normal student'. From the majority of the policy documents reviewed, policy documents acknowledge that the student-supervisor relationship is important. However, they do not provide guidance on how to enhance the nexus, only what to do if it breaks down, i.e., appeals, disciplinary, etc.

This emphasis suggests that it is not the student-supervisor relationship that is the key, but protecting the institution from student complaints. The UK Quality Assurance Agency for Higher Education (QAAHE) code of practice for postgraduate research (Quality Assurance Agency for Higher Education [QAAHE], 2012) shows what is expected with regard to research supervision. This document does not mention anything about the student-supervisor relationship. It only ensures that supervisors who are selected by the institution to supervise are fit for purpose as well as ensuring that the university has appropriate systems and procedures for recruiting, selecting, and inducing students into the university, in conjunction with mechanisms to deal with staff and student complaints, i.e., "there are procedures by which either the candidate or the supervisor may make representations as appropriate as significant difficulties arise (grievance procedures)" (QAAHE, 2012, chapter B11). The policy documents reviewed tended to assume that institutions, staff, students, and research can be managed in a mechanistic manner. Based on the analysis of the policy documents and supported by the primary data collected, which is presented below, the notion of research supervision being seen as a machine is evident.

The fundamentals of the machine metaphor are that the process of supervision has a purpose or goal that functions in a predetermined and predictable way. The performance of the machine can be gauged and adjusted to achieve peak productivity. The machine is designed and built in a rational way with all parts of the machine working together to produce some output. The parts of the machine can be replaced when they wear out or no longer function properly, and the machine will function as before. They tend to ignore, or fail to articulate, the human side of institutions and the human face of research and supervision.

Policy documents may be perceived by senior managers to enhance practice, but they do not actively engage the community of supervisors. In essence these documents tend to the notion of a 'thou shall do' doctrine. Indeed, supervisors may be tempted to see their interaction with the policy as a game. Nevertheless, it is assumed that in some cases this may have indeed helped students, who prior to New Managerialism, may not have received a rudimentary entitlement to research supervision.

Given the often seen 'tick box mentality' of such imposed quality regimes and based on the policy document analysis and supported by primary data presented below, an additional concept of playing the game emerges, i.e., giving the central services of the university what they want and then getting down to the real business of supervising the student.

The game metaphor is one of the more popular metaphors describing human endeavor today. A game can be a cooperative game where players collaborate with one another to achieve an objective. A game can also be competitive where teams of players try to prevail. A common theme of all games is that players engage in activities to achieve some goal or objective. The players must continue to support one another to create and develop the most powerful ideas they can, but these ideas will have to compete with other ideas for acceptance, hence the supervisor and the student may work together to play the game and win a successful project supervision for the supervisor with no complaints and a successful mark or grade for the student. This may mean that a relationship is formed for mutual gain and benefit rather than purely supporting the student to learn.

What may be missing from the policy documents is that research supervision can be viewed as a garden, where the supervisor tends the garden (the student) like a coach to allow the student to 
grow and learn. The skill of the supervisor affects the structure and a plan of what and how students will learn and in how they implement the research. However, within that plan there is usually some randomness and disorder evident, as is also evident in a garden. The reason behind this may be, to quote Shulman (2005), "I would say that without a certain amount of anxiety and risk, there's a limit to how much learning occurs. One must have something at stake. No emotional investment, no intellectual or formational yield" (p.1).

What is interesting from the policy documents is the idea that there is a standard template on how to supervise anybody from any discipline in any topic area. This assumption is questionable. The research process is complex and each discipline has its own body of knowledge and its own ways of looking at knowledge and undertaking research. This mind-set runs counter to Wilhelm von Humboldt's view of higher education, "[t] he relationship between teacher and learner is ... completely different in higher education from what it is in schools. At the higher level, the teacher is not there for the sake of the student; both have their justification in the service of scholarship." Humoldt (1810, p.242).

Many universities have developed research supervisors' handbooks, given the need for greater accountability and control, associated with New Managerialsim, which contains what must happen and what to do if things do not happen. This usually relates to providing formal roles, duties, and responsibilities of both supervisor and student in the postgraduate research process. However, the actual 'handbooks', which are policy documents, are static and exhibit a view of the time, at that time. Yet the process of postgraduate supervision is endowed with meanings, sometimes stable, sometimes confused, sometimes misunderstood, sometimes used for political and power issues, sometimes assumed, sometimes ignored, sometimes contested, and sometimes shared, which is the heart of supervision process. Despite this, we have moved away from looking at the process of being a supervisor towards the substantive defendable output of what has been done by the supervisor.

In order, to return to the 'being' a supervisor, it was necessary to explore the views and experiences of academics who supervise. The process of constantly re-visiting the data, sharing it with colleagues, and discussing it with a wide range of audiences provides the opportunity for identification of data which is questionable and idiosyncratic in the eyes of practitioners. Validity in their eyes is important in establishing confidence in moving towards conclusions, however provisional they may be.

\section{Research Design}

A phenomenological approach was used to guide and provide the necessary philosophical and methodological research underpinning to the project. We examine the ways that narrative structures our perception of both cultural artifacts and the world around us. Such an approach is needed when exploring supervisors' perceptions of supervising. Given this, our ordering of time and space in narrative forms constitutes one of the primary ways we construct meaning in general. Narrative can be viewed as 'lived stories' on a particular situation (both the content and the context).

One of the early pioneers of this approach [narratology] states, far from being one code among many that a culture may utilize for endowing experience with meaning, narrative is a meta-code, a human universal on the basis of which transcultural messages about the nature of a shared reality can be transmitted (White, 1987). As an interdisciplinary method, we draw from traditions in literary theory, oral history, drama, psychology, folklore, and film philosophy (Connelly \& Clandinin, 1990; Marshal \& Rossman, 1995).

The theme of storytelling and the didactical power of the storyteller's voice are important in establishing what supervisors think. The intellectual justification is that one may understand a 
story with the conception or world view and one may use the story of another. In this way we are able to learn how to understand the world from a different view. Narrative inquiry is appropriate here since it can establish meaning that lies behind responses of collaborators and it is able to establish uncertainties and ambiguities surrounding research supervision. Allied to this, narrative gives an 'insider's' viewpoint to the realities that enshroud this phenomenon.

The methodology justification for narratives is based on the notion of collaboration. It allows and actively seeks the voice of the collaborating parties and it helps to reduce the impact and/or polluting interpretations of what is being said by the traditional objective researcher, so that a more realistic view is obtained. Finally, narrative does allow others to relive and interpret the 'story', thus bringing about a positive change in practice.

\section{Primary Data Collection}

Five personal narratives were sought from the practicing academics who regularly engage in postgraduate supervision, in order to ascertain their experiences of what makes a good supervisor of a student and to reflect on these experiences. Each of the participants began the process of unpacking how they became good supervisors (as constructed by themselves) by constructing a short reflective statement. The reflective statement was designed to prepare the supervisors for an extensive narrative session with the authors, by initially prompting them to reflect on how their own approach yielded effective supervision. Three types of question were used to help bring a degree of structure to the narrative session. Each narrative session focused on identifying the relationship with the student, what the supervisor did for the student and what the student did for the supervisor, and provided some contextualisation about the university, the business school, the nature of higher education, and what the supervisor thought the nature of being a professional was at the time of supervision.

The practicing academic story tellers were all co-workers of two of the authors, within one UK University, which was a post 1992, ex-polytechnic university, whose focus was on teaching informed by research curricula. A pilot narrative session was performed to allow the authors to familiarise themselves with the technique and to practice facilitating the session to ensure that sufficient ground was being covered that was of benefit to the study. The pilot was undertaken with non-collaborative individuals who were not subsequently involved in the study further.

Narrative sessions were taped. Each session lasted around forty minutes. Three sessions were completed. Each narrative session was played back numerous times to aid the analysis by the authors and to capture the richness of the data. A full written transcript was not undertaken. This was due to time constraints and also that a $100 \%$ complete transcript records of the event is impossible to achieve, as it depends upon what you are trying to do in and with the analysis (Silverman, 1993). The tapes were played to identify the creation of categories, which allowed themes and emergent issues and ideas to be extrapolated from the data. The authors found this more economical and effective.

Several meetings took place in the same room (five individual narrative sessions, five additional individual refinements of conceptual model sessions, and one group session which developed the non-contentious primary task consensus model). The room was laid out with a horseshoe of chairs to encourage discussion and debate, with a flip chart facing the group, with tea and coffee available to participants to create a relaxed and informal atmosphere conducive to discussion. Each collaborator was willing to be tied by an ethical code of conduct, to respect each other's views and not to damage one another physically, emotionally, or intellectually. Also, the issue of 'over-disclosure' (Bloor, Frankland, Thomas, \& Robson, 2001) was covered. If over-disclosure occurred then the facilitator (researcher) would enact certain remedies and actions made clear to the participants in advance. 
The sample consisted of:

- one programme leader, who was research active, with a teaching role, who was a seasoned Professor, who undertook PG and Doctorate level supervision \{participant one\};

- one academic director of IS who is research active and a seasoned senior lecturer, who had a minor teaching and supervisory role \{participant two

- one director of academic enterprise consultancy, a newly appointed senior lecturer, not research active, with several years lecturing experience, who was supervising for the first time $\{$ participant three\};

- one seasoned senior lecturer, no longer research active but who had a teaching role, who supervised PG and Doctorate level students \{participant four\};

- three seasoned lecturers, both research active and who had a teaching role, who supervised PG students \{participants five, six and seven\}.

In this study the majority of the respondents felt that most postgraduate supervisors learn the importance of the supervisory relationship and what makes a good supervisor by reflecting on their own, sometimes disappointing, experiences of being supervised. Experts know what to do at a given time based on their knowledge of the content and knowledge of the context, as they actively engage with society via discussions. However, it is very difficult to unlock tacit knowledge completely, as it becomes automatic, like touching your nose with your eyes shut. Narrative combined with an interpretive research stance does provide a mechanism to attempt to unlock this knowledge to some extent via storytelling and by exploring how the supervisor interacted with the student, colleagues, the institution, and the subject matter at that time. However, this approach is limited. As Polanyi (1974) states, we know more than we can tell and that knowledge may never be fully captured retrospectively, as the context cannot be completely reproduced.

Grounded theory was used to help shape the research design. Grounded theory as developed by Glaser and Strauss (1967) allows the researcher to break away from the classic research model towards developing and elaborating on theory, rather than testing theory in practice (Bechhofer \& Paterson 2000). This is important as research into Masters level research supervision is still embryonic and as such there is limited theory to test. As such, it was necessary to use grounded theory to inform and challenge the data collected in an interactive manner, to ensure the right issues were being identified, investigated, and analysed where possible. The bottom up approach is manifested via the development of a non-contentious primary task conceptual model discussed below.

\section{Problematic Issues of Narrative}

Although narrative is a suitable research method for this project, there are a number of issues, which can be regarded as problematic. One of the main criticisms of narrative is that it focuses on the individual too much. However, given the multiple interpretations of meanings of key words and the emotions that people have surrounding key words and concepts used in the narratives, it is conceivable that combining narratives does not truly arrive at a consensus. What the collaborative group may have experienced is power and political interplay being exercised to give the illusion of a consensus being reached. Narrative at best gives an awareness and appreciation of a phenomenon. However, it is difficult to make specific claims about reality, truth, and knowledge based on narrative and the interpretation of such data due to the inherent methodological weaknesses.

Narrative inquiry is also difficult to perform, since a significant amount of sensitivity, trust, and goodwill to negotiate has to exist between the researcher and the collaborative participants. Narrative can provide some inroads to this area, but it requires intense listening and a willingness of the researcher to give the participant a full voice. Since narrative is collaborative in essence, both 
the researchers and the participants' voices are heard as they are working together to make sense of their view of reality. Like other forms of qualitative analysis, narrative does suffer from selective recall, in which the gap is filled in by inference and reinterpretation of the past events (Ross and Conway, 1986, as cited in Marshal \& Rossman, 1995), rather than on fact. Since the nature of narrative is qualitative, it gives the illusion of causality as the collaborators can infer a connection that may not be there. This is not to say that narratives do not provide insight and yield enriched data. It is more a question of to what degree and what can be claimed on behalf of a wider population? Nevertheless, to do collaborative research well requires the researcher to be patient, flexible, and trustworthy and have honed negotiation skills.

From the point of view of the efficient use of resources, narrative is very time consuming, as it requires the recorder to actively listen and be able to quickly establish a supportive constructive environment and be able to work with others in such an environment. Very few people have these skills. All of this is compounded by the fact that narrative is still a relatively new form of research inquiry, which means there is no established modus of operandi to help the novice user of narratives use narratives, and perhaps the only true way to understand narrative is via reflection.

\section{Data Analysis and Findings}

The development of a conceptual primary task model was utilised as a research tool to determine the presence of certain words and or concepts within each of the narrative sessions. At the core of this analysis is that words and signs can be assigned to conceptual categories and that these categories can be tested to reveal the importance of the idea by the way in which they are used in the narrative. In summary, the researcher searches for structures and patterned regularities in the words and makes inferences based on these regularities as the meanings are shaped in the context of the exchange between respondents (Silverman, 2000). The development of the conceptual model was informed by the use of grounded theory to bring order, structure, and meaning to the mass of data collected. The data was thoroughly reviewed to become familiar with the categories, themes, and patterns that were unpacked. Salient themes, recurring ideas and language, and regularities were all noted, which allowed categories of meaning held by the participants in the setting to emerge.

Based on the analysis, the supervisors appear to recognize a process for supervision, with each supervisor accepting to a lesser or greater extent what the other stages are, but favouring a particular stance. Nevertheless, all agreed that all they could offer was "their time and their experience" and that supervision was "time consuming" and "a good working relationship with the student was necessary" and that "students must receive constructive and critical written comments and feedback on drafts that they submit and that work should be returned quickly as laid down by the rules and regulations of the duties of supervision by the university" (participant two .

Following Lee and Green (2009) we therefore identify three useful metaphors for consideration within the process of research supervision.

\section{(A) Metaphor of the Machine}

From the analysis of all three individual perceptions, coupled with the findings from the policy documents (presented earlier), an element of "doing what the policy said" \{participant three\} appeared, as all collaborators had some form of human activity that suggested monitoring and control of the student's work, e.g., "one of the duties of a supervisor was to monitor the students' performance in line with the University regulations" \{participant one\}. Given the history and organisational Managerialist culture that exists within the Business School, this is not surprising. 
A number of the collaborators indicated the following activities as being some of the ingredients to providing good supervision.

From their views of reality, the key ingredients were to "be accessible to the student to ensure that they cannot complain to the associate dean of research, that they are not getting the support and help they need and are entitled to given the fact that they are paying their fees" \{participant six $\}$. What is interesting is that all the supervisors kept a supervisors log relating to each student they supervised. When asked whether this made them a good supervisor, the answers were mixed. One of the collaborators completed the log and gave a copy to the student outlining what was discussed and what was expected for the next meeting. Their rational was one of "providing additional formative feedback to the student" \{participant two and to use the data as evidence of the supervision process and their activity in the supervision process. This was all done in event that the student complained or the Dean or the Head of department requested a progress report on the student in addition to the formal monitoring phases. Other collaborators completed such logs as it was expected within the "rule book" \{participants five and six but they only completed it for their own needs and all cited the issue of providing evidence to a university committee if the student complained about them.

All the collaborators commented upon the need to manage the expectations of the student. "You need to be upfront with the student with regards to what is expected, when it is expected, in advance to prevent any misunderstandings and future consequences" (participants one, two, three and four \} was a common comment. This is interesting as the students expectations were seen as a way of establishing a relationship for dialogue and discussion with the student. However, when probed, it was not the expectations of the student that was important, but how the supervisor perceived the students planned methodological, thinking, argument, and structure of the work. Comments like, "the supervisor has to control the process", "the supervisor is responsible for quality" \{participant one\} and "My real bug bear is the student who does not produce output and when they do, the output is developed in a way that is unnecessary" \{participant two were evident but not widespread. This indicates that it is not solely the management of the student's expectations (which is discussed in the next section) but management of the supervisor's expectations of the student and of the work that is deemed important.

One of the collaborators was an advocate of only doing what was stated in the policy document and that, as a supervisor "students had to listen to them and that if a student did what they were told then they would pass" \{participant three\} and "each research student is an apprentice who has to learn the mechanisms of research from an older more experienced person" (participants one and three\}. What is interesting is that the supervisor has an air of superiority and the idea that research is mechanistic, rather than a craft, which illustrates the complexity of the supervision process.

This rather didactic approach of the supervisor, completely ignoring the needs, thinking (development within), and contribution the student can make to the area of study, is mechanistic. It is this machine like manner which policy documents may encourage. Policy documents only pay a passing token gesture to the student actually learning and developing as individuals and perhaps more importantly as the next generation of researchers. It is this last point that at the collaborators group discussion session (when the group developed the non-contentious consensus primary task conceptual model) caused the greatest debate and required strong mediation skills from the authors. It became apparent initially that one of the collaborators was an advocate of this Managerialist approach. However, during the group discussion, this was not indeed the case, as when they spoke of "us" and "them" \{all participants\} they meant colleagues to the exclusion of students. 
It became apparent that they wanted to provide students with more help but they wanted to do what management had told them to do, even though on earlier occasions they had told management that the policy was incomplete and detrimental to the students learning. They were willing to play the game and to do what was commanded, in order to make a political statement to senior management. They would concentrate on the needs of the student when "management came to their senses" \{participant two .

\section{(B) The Metaphor of the Coach}

Most participants agreed that supervisors should not "over supervise the student" \{participants two, three, four, five, six and seven $\}$ as it was the student's work and they did not feel the right to act as a censor of the work. Most agreed that they were there only to provide advice about the work. They preferred the concept project advisor, as most felt 'supervisor' gave the wrong impression of what their work was about, i.e., it was not exclusively about control and monitoring, but more of a "critical friend" \{participants two, three, four, five, six and seven or a coach, giving their experience and knowledge of problems and "to advise solutions that were appropriate to the limitations and the capabilities of the student" (participants one, two, three, four, five, six and seven (like a sports coach).

As an advisor to the student, the role of supervision is much wider than that of the actual project under supervision. One of the roles of a good supervisor is to "build the confidence" \{participant one of the student and to provide the student with a wider access of networks, for example, other students who are studying the same or similar areas of study, companies for case studies, people to interview, a library of previous publications, help in finding a job, career advice for that cognate area, to write references, help with CV writing, etc.

Of those collaborators who shared this view, they indicated that the supervisor had to be completely honest with the student and that the key was "to listen to the student and to fully discuss issues relating to theory, methodology, content and getting the project done" (participants one, two, three and four\}.

All agreed that the departure away from the policy rulebook towards this interpretation of the duties and roles of the supervisor meant "every supervisor has to find their own style" participant one , and that as supervisors "You learning from trial and error and from more experienced colleagues" \{participants five, six and seven\}.

\section{(C) Metaphor of the Journey}

The idea that research supervision was more like a partnership and a research journey, where the student and supervisor learn together, was not universally shared by all the collaborators. Nevertheless, perhaps it is this view which provides a missing dimension as to what makes a good supervisor.

Some of the collaborators did see this as a rather 'romantic' and ideological view of supervision and of higher education in general, but felt that it did have some merit and therefore limited inclusion in the agreed conceptual model. The issue here would be whether those people who think that this view is romantic may indeed not be research active themselves; therefore, they have no wish to undertake the journey.

One collaborator's view was that a key sub-set of skills a supervisor must have is to be "passionate about the area of study" (participant one\} and to be "enthusiastic about learning and learning with and from others" \{participants one and two and that advanced academic "scholarship was the key, as supervisors need to lead by example and help light the fire of the students imagination and curiosity" \{participant two . 
In order to facilitate this view, supervisors have to "build and maintain an active research profile" \{participants two, three, five, six and seven and "allow the student to be critical of their work" \{participants two, three, five, six and seven\} in a process of constructive dialogue and negotiation. "Supervision is about the continual exchange of ideas and supervisors should refrain from talking about students and see and treat them like junior colleagues eager to learn and research" \{participant one\}.

This partnership, where the supervisor guides the student and navigates with the student along the research journey, is the only way to generate or discover new knowledge, as the junior colleague has new eyes and the supervisor has the experience to see it through them. Together they both colearn and challenge what has gone before. Nevertheless, metaphor (b) and to a lesser extent, elements of metaphor (a) are needed in addition to metaphor (c) to ensure that both the student and the supervisor reach the final destination of a completed thesis safe and sound. As research, supervision is simply "collaboration plus explanation" \{participant one\}.

The rationale behind this co-learning partnership can be summarised by the American authors Andre and Frost (1997) when they state:

"Professors can contribute to society if they provide better students, individuals who can think critically and broadly and who become enthusiastic about learning. If we want narrowly focused, passive learners who are organisational conformists and pallid citizens, then give them rote learning from a canned curriculum, not taught by professors. If we want organisational innovation and problem solvers then expose students to people like these who are themselves working enthusiastically at the cutting edge of their fields. Our contributors seem to have known instinctively that a crucial part of teaching students to learn is to model being a learner themselves through demonstrating, among other things, curiosity, passion, commitment of time and resources and a spirit of playfulness. Professors who believe that their discipline is important empower students to see the world through a particular lens, and the experience of an aggregation of many lenses in education". (Andre \& Frost, 1997, pp x).

The multidimensional nature of supervision and what this means to academic professional practice is extremely debatable. This paper presents an agreed view of what makes a good research supervisor; it does not offer a complete solution but more a deconstruction of practice, which offers solutions not final outcomes (Stronach \& MacLure, 1997). This research has also established that the most important ingredient in successful postgraduate supervision was not solely being a scholar in the field but building an effective professional relationship with the student. In many cases this involved modelling good research practices, but in just as many cases it required encouraging students regardless of the supervisor's personal opinions of their work and learning the craft of research via trial and error. Nevertheless, there was still a strong need to monitor and control the student to some extent.

To assist new and seasoned supervisors to reflect upon their own professional practice the following conceptual model (Figure 1) is proposed. In short, this was the agreed view of the participants in this research. The conceptual model presented here is not a one 'standard' approach to supervision, but an approach that has the degree of variety, flexibility and elasticity to match the complexities in the situations to which it is applied. Its core is the construction of a logical and defensible purposeful set of activities which individual academics can then compare with their own practices. The intention of the model is derived from following Soft Systems Methodology (Ackoff, 2010; Checkland, 1981; Checkland \& Poulter, 2006). A purposeful statement (root definition) is something that seeks to identify, capture, and measure potential worldviews of what the 'system' should be (rather than what it is currently or how it currently operates) in detail. All purposeful statements are developed in accordance with what the 'system' should do, what sup- 
port mechanisms are needed to support its transformation, what the environmental linkages and issues are that have to be considered, and what monitoring, controlling, and corrective action is needed to achieve what the system wants to achieve.

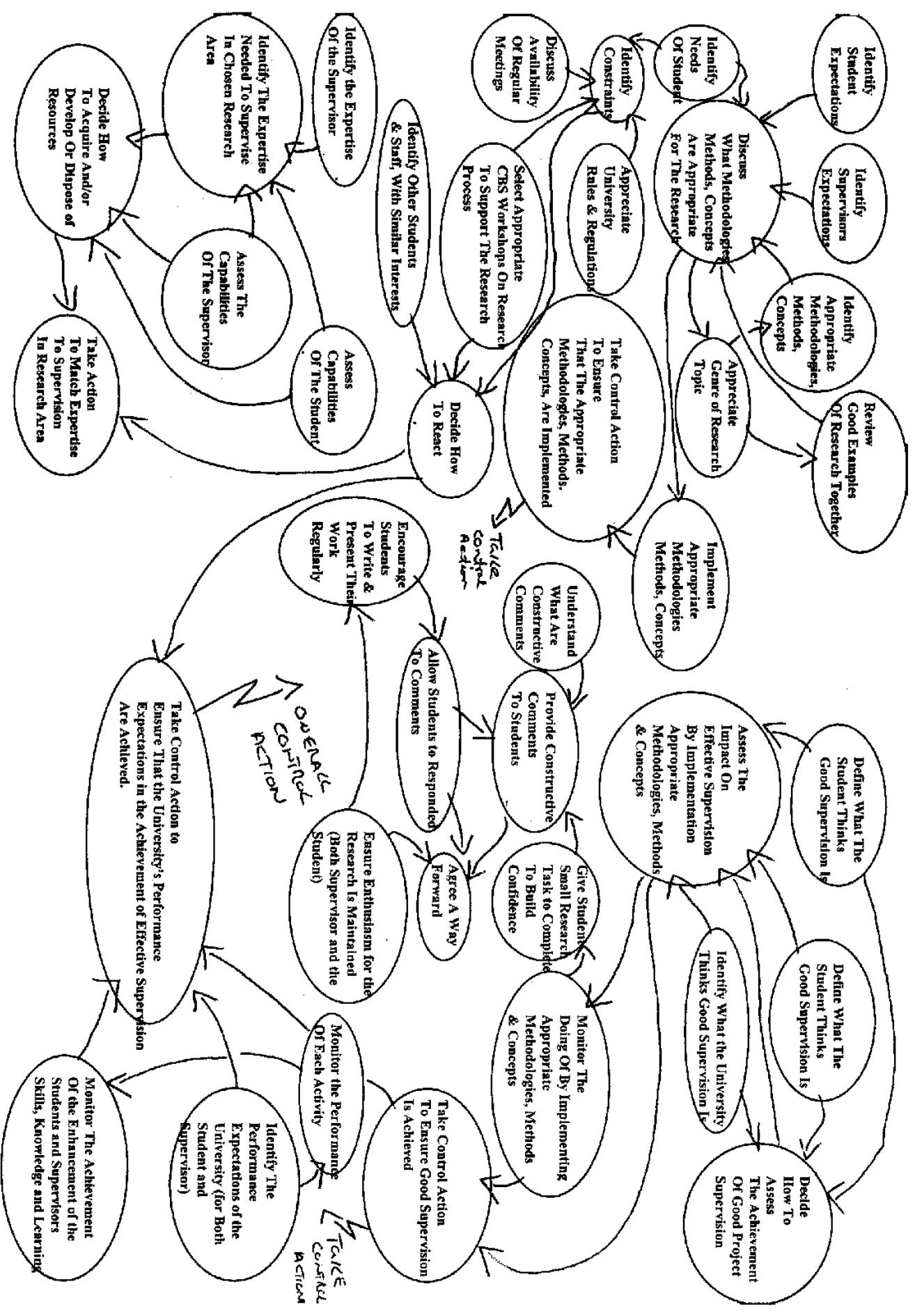

Figure 1. Model to aid Reflective Supervision Practice 
Worldviews are usually obtained via one-to-one interviews or with stakeholder groups. For the model presented in Figure 1, the purposeful statement is a university owned system, operated by research supervisors and research students to undertake academic research work and to enhance the skills, knowledge, and learning of both the supervisor and the student by using appropriate methodologies, methods, and concepts, in an environment which encourages free useful and constructive discussion within the academic constraints of that cognate area and the rules and regulations of the University and the abilities of the student and the supervisor. Given this statement, a model is developed that is a set of logical dependant 'hows' which achieve the statement. If one was to change the statement, then the model would need to change and vice a versa. The model can then be used by the individual academic to review in a reflexive way their own practices.

The study supports earlier work undertaken by Kandblinder and Peseta (2001) when they state that supervisors describe their approach to supervision as a result of experimentation until they formulated a scheme that worked for them. In discussing their motivations for becoming better supervisors, it was clear that experienced supervisors had been reacting to their own experiences of being research active (where relevant). Whether their own relationship with their supervisor was a productive experience, which they sought to emulate or, more commonly, as a negative experience they wished to avoid, it is clear that successful supervisors are typically thoughtful about how to supervise and they draw on a range of approaches to suit the student's individual circumstances. It was evident from the narratives that most supervisors saw themselves as advisors and/or co-learners in the supervisory relationship (Figure 1).

\section{Conclusion}

The research identified that the most important ingredient in successful postgraduate supervision was not solely being a scholar in the field but building an effective professional relationship with the student. In many cases, this involved modelling good research practices, but it also required encouraging all students regardless of the supervisor's personal opinions of their work and learning the craft of project supervision via trial and error. Taking this work a speculative stage further, perhaps a new research supervisor pedagogy is needed, that of 'dissensus'. A pedagogical emphasis on 'dissensus' allows supervisors "to support learners in the development of their ability to hold paradoxes and not be overwhelmed by complexity, ambiguity, conflict, uncertainty, and difference" (Andreotti, 2011, p.395).

Nevertheless, there was still a strong need to monitor and control the student to some extent and to ensure that the supervisors themselves and to a lesser extent the student, conformed to universities policy requirements. As such, while providing a degree of regulatory and competence comfort for the student, the supervisor also learns through reflective and reflexive practice. Indeed, this is essence of learning and represents the heart of the academy and faculty/education. Finally, we as academics must remember the words of Paolo Freire (1970) - apart from inquiry, apart from praxis, individuals cannot be truly human, i.e., "Knowledge emerges only through invention and re-invention, through the restless, impatient, continuing, hopeful inquiry human beings pursue in the world, with the world, and with each other."

By positing the model, we hope colleagues will engage in being reflective practitioners, which we contend is the bedrock of being a good supervisor, as reflecting upon performance and acting on reflection is one of the defining attributes of being a modern academic.

\section{References}

Ackoff, R. (2010). Systems thinking for curious managers. Triarchy Press. 
Anderson, C., Day, K., \& McLaughlin, P. (2006). Mastering the dissertation: Lecturers' representation of the purposes and processes of master's level dissertation supervision. Studies in Higher Education, 31(2), 149-168.

Andre, R., \& Frost P., J. (Eds.). (1997). Researchers hooked on teaching, noted scholars discuss the synergies of teaching and research. Foundation for Organisational Science, California: Sage Publication.

Andreotti, V. (2011). Relativizing western knowledge production in spaces of dissensus The OSDE methodology. In V. Andreotti, Actionable postcolonial theory in education (pp.191-216). Retrieved from http://www.palgraveconnect.com/pc/doifinder/10.1057/9780230337794.0020

Bechhofer, F., \& Paterson, L. (2000). Principles of research design in the social sciences. London Roultledge.

Black, D. (1994). A guide for research supervisors. Cambridge, UK: Centre for Research into Human Communication and Learning.

Bloor, M., Frankland, J., Thomas, M., \& Robson, K. (2001). Focus groups in social research. London: Sage.

Brown, S., \& McIntyre, D. (1993). Making sense of teaching. OU Press.

Checkland, P. (1981). Systems thinking; Systems practice. NY: John Wiley \& Sons.

Checkland P., \& Poulter, J. (2006). Learning for action: A short definitive account of soft systems methodology and its use practitioners, teachers and students. John Wiley \& Sons.

Clarke, J., \& Newman, J. (1997). The managerial state: Power, politics and ideology in the remaking of social welfare. London: Sage.

Connelly, F., M., \& Clandinin, D., J. (1990). Stories of experience and narrative inquiry. Educational Researcher, 19, 2-14.

Cooper, P., \& McIntyre, D. (1996). Effective teaching and learning: Teachers and students perspectives. OU Press.

Corbyn, Z. (2009, July 12). Leading academic attacks tick-box science and politically correct quackery. Times Higher Education Supplement. Retrieved 27th March 2014 from http://www.timeshighereducation.co.uk/news/leading-academic-attacks-tick-box-science-andpolitically-correct-quackery/407337.article

Cullen, D., J., Pearson, M., \& Saha, L., J. (1994). Establishing effective PhD Supervision. Australian Government Publishing Service, Canberra.

Freire, P. (1970). Pedagogy of the oppressed. (M. B. Ramos, Trans). New York: Continuum.

Glaser, B. G., \& Strauss, A. L. (1967). The discovery of grounded theory: Strategies for qualitative research. New York: Aldine Publishing.

Grant, K., Hackney, R., \& Edgar, D. A. (2003). Managerial academia: Towards the harmonization of the profession. Journal of Informatics Education \& Research, 5(2), 1-15.

Hardee, K., Feranil, I., Boezwinkle, J., \& Clark, B. (2004). The policy circle: A framework for analyzing the components of family planning, reproductive health, maternal health, and HIV/AIDS policies. U.S Agency for International Development (USAID). Accessed $7^{\text {th }}$ April 2014 from http://pdf.usaid.gov/pdf docs/pnacy528.pdf

Humboldt, W. von (1810). On the spirit and organisational framework of intellectual institutions in Berlin. reproduced in Minerva, 8(2), April 1970, pp. 242-267

Kandlbinder, P., \& Peseta, T. (2001). Report - In supervisors' words....An insider's view of postgraduate supervision. Institute for teaching and learning, The University of Sydney.

Kolsaker, A. (2008). Academic professionalism in the managerialist era: A study of English universities, Studies in Higher Education, 33(5), 513-525. 
Lave, J., \& Wenger, E. 1991). Situated learning: Legitimate peripheral participation. Cambridge University Press.

Lee, A., \& Green., B. (2009). Supervision as metaphor. Studies in Higher Education, 34(6), 615-630.

Lynch, K., Grummell, B., \& Devine, D., (2012). New managerialism in education: Commercialization, carelessness and gender. Palgrave Macmillan.

Marshal, C., \& Rossman, G. B. (1995). Designing quality research (2nd ed.). Thousand Oaks: Sage.

Moses, I. (1985). Supervising postgraduates. Higher Education Research Development Society of Australasia, Green Guide No. 3. Sydney: TERC, University of New South Wales.

Moses, I. (1992). Research training and supervision. Proceedings from the ARC and AVCC sponsored conference in Research Training and Supervision held at Canberra in May, 1992. (AVCC and ARC, Canberra).

Polanyi, M. (1974). Personal knowledge towards a post critical philosophy. NY:Harper \& Row.

Pollitt, C. (1990). Managerialism and the public services. Oxford: Blackwell.

Quality Assurance Agency for Higher Education (2008). The framework for higher education qualifications in England, Wales and Northern Ireland. Accessed 7 March 2014 from http://www.qaa.ac.uk/Publications/InformationandGuidance/Documents/FHEQ08.pdf

Quality Assurance Agency for Higher Education (2012). UK quality code for higher education - Chapter B11: Research degrees. Cheltham, Gloucester last accessed 7th March 2014 from http://www.qaa.ac.uk/publications/informationandguidance/pages/quality-code-B11.aspx

Shulman, L. S. (2005). Pedagogies of uncertainty. Association of American Colleges and Universities. Retrieved 11th March 2014 from http://www.aacu.org/liberaleducation/le-sp05/le-sp05feature2.cfm

Siddle, D. (2001). Preface. In P. Kandlbinder \& T. Peseta, Report - In supervisors' words....An insider's view of postgraduate supervision. Institute for teaching and learning, The University of Sydney.

Silverman, D. (1993). Interpreting qualitative data: Methods for analysing talk, text and interaction. London: Sage.

Silverman, D. (2000). Doing qualitative research: A practical handbook, London: Sage.

Stronach, I., \& MacLure, M. (1997). Educational research undone: The post-modern embrace. Buckingham \& Philadelphia: Open University Press.

Todd, M., Smith, K., \& Bannister, P. (2006). Supervising a social science undergraduate dissertation: Staff experiences and perceptions. Teaching in Higher Education, 11(2), 161-173.

White, Hayden. (1987). The content of the form: Narrative discourse and historical representation. Baltimore: Johns Hopkins University Press.

\section{Appendix: Policy Documents}

\section{Monash University}

Supervisors Strict Code of Conduct for Research Supervisor. Accessed 24 February 2014 from http://www.monash.edu.au/migr/research-degrees/handbook/chapter-five/5-2.html

\section{University of Sydney}

Supervision Roles and Responsibilities. Accessed 24 February 2014 from http://sydney.edu.au/policies/default.aspx?mode=folder\&uri=4603102

\section{Glasgow Caledonian University}

Internal Intranet Site - Assessment Regulations. Accessed 24 February 2014 from http://www.gcu.ac.uk/media/gcalwebv2/theuniversity/gaq/gaqfiles/University $\% 20$ Assessment $\% 2$ 0Regulations $\% 202013$ 14.pdf 


\section{The Robert Gordon University, Scotland}

Guidelines: Good Practice in the Supervision of Undergraduate and Postgraduate Projects and Dissertations. Accessed 24 February 2014 from https://www.rgu.ac.uk/about/academic-affairs/assessment-policies-and-procedures/guidelines

\section{University of Groningen}

PhD Regulations. Accessed 24 February 2014 from

http://www.rug.nl/education/phd-programme/promotieregeling/phd-regulations-2014.pdf

\section{Biographies}

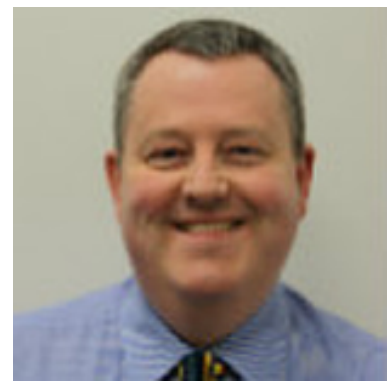

Dr Kevin Grant is currently Head of Department: Informatics at London South Bank University, UK. His main research interests are in business strategy informed by disruptive technological innovation, business modelling, IT alignment, Technological based Innovation focusing on leveraging disruptive technologies to drive growth and value (management of innovation, creativity, invention, diffusion, alliances and networks and commercialisation, open and user based innovation and the management of intellectual property) and finally, on Academic Enterprise (the nexus and Triple Helix between teaching, research, scholarship and consultancy).



Professor Ray Hackney is Chair in Business Systems within the Business School at Brunel University, UK. He has contributed extensively to research in the field with publications in numerous national and international conferences and journals. He has taught and examined on a number of Doctoral and MBA programmes including Manchester Business School and the Open University. He led the organising committee for the annual BIT and BITWorld Conference series and is a member of the Strategic Management Society and Association of Information Systems. Professor Hackney has served on the Board of the UK Academy for Information Systems since 1997 and was also the Vice President Research for IRMA (USA). He is currently Associate Editor of the JGIM, JEUC, JLIM, ACITM, EJIS and case editor for IJIM. His research interests are the strategic management of information systems within a variety of organisational context, with an increasing speciality in government sectors and has he has contributed to a number of EPSRC and European funded research projects. Professor Hackney was President of the Information Resource Management Association (IRMA) during 2001/2002 and is now an Executive Member of the Information Institute www.information-institute.org

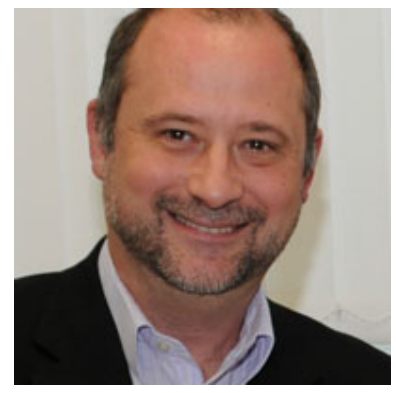

Dr David Edgar is Professor of Strategy and Business Transformation and member of the Department of Business Management at Glasgow School for Business and Society. His main areas of research and teaching are in the field of strategic management, specifically dynamic capabilities, business uncertainty and complexity, and innovation. He has worked with a range of organisations on Business Transformation projects in particular relating to e-Business strategies, innovation, and knowledge or talent management. David's interest in innovation relates to innovation as an element of dynamic capabilities. 